\title{
Runolaulun poetiikka
}

\author{
Lectio praecursoria Helsingin yliopistossa 20.1.2018
}

\author{
Jukka Saarinen
}

$V^{\prime}$

enankarjalainen, vuoden 1769 paikkeilla syntynyt Arhippa livananpoika, livanaińi Arhippa, Perttusen sukua, on tunnetuimpia kalevalaisen runon taitajia. Arhipan maineen loi Elias Lönnrot, joka sai häneltä keskeistä runoainesta Kalevalaan ja joka ylisti Arhippaa ja Kesälahden Juhana Kainulaista parhaiksi laulajiksi, jotka oli tavannut.

Mikä oli sitten se Arhipan erityisyys, joka sai Lönnrotin ja Lönnrotin jälkeen monet muut toteamaan hänen

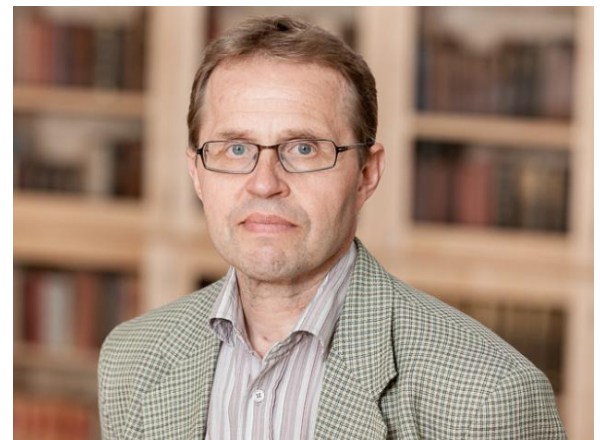

Jukka Saarinen (Kuva: SKS) etevimmyytensä?

Arhipan laulajuuden kokonaiskuvassa on monta kerrosta, joita voidaan kuoria ja analysoida. Ensimmäinen kerroksista on Lönnrotin. Sen yksi tekijä on kvantitatiivinen: Lönnrotin tallentama säemäärä on suurempi kuin kenenkään muun pohjoisen laulajan. Saadaan mennä Karjalan kannakselle ja Inkeriin asti ennen kuin tavataan yhtä runorikkaita laulajia. Toinen tekijä on Lönnrotin subjektiivisempi arvio Arhipan runojen selkeydestä: mitä tarkoittaa hänen mainitsemansa "laulaminen hyvässä järjestyksessä ja ilman suurempia aukkoja"? Arhipalla on pitkiä runokokonaisuuksia, joiden kerronta etenee jotensakin johdonmukaisesti ja joiden siirtymät aiheesta toiseen ovat ainakin joillain assosiaatioilla perusteltuja. Runot ovat "aukottomia" mutta kääntöpuolena saattavat olla yksityiskohdissaan pelkistetympiä kuin muiden vastaavat runot.

Otan esimerkiksi sen runon alun, jossa Väinämöinen kuulee purren itkevän, lähtee merelle, törmää luotoon ja rakentaa kanteleen. Arhipan poika Miihkali, kuten lukuisat muut laulajat Vienasta Inkeriin, kuvaavat Väinämöisen olevan suorittamassa tiettyä tehtävää, kun hän kuulee purren itkevän:

\footnotetext{
Vaka vanha Väinämöińi,

Läksi oštoho orihiñ,

Kulo-harjan kuunteluȟe,

Šuvi-kunnan šuitśet vüöllä,

Varšan valjahat olalla.
} 
(SKVRI 617:1-5.)

Arhippa lähettää Väinämöisen päämäärättömälle kävelylle ympäri meren sinisen. Miksi? Yksi selitys voisi olla, että Arhipan runo edustaa puhtaampaa ja alkuperäisempää kantaa, mutta kun katsotaan motiivin yleisyyttä ja levikkiä, se ei ole kovin todennäköinen. Toinen vaihtoehto olisi pitää tätä unohduksena, ehkä keruutilanteen aiheuttamana poikkeamana. Tämä on mahdollista. Vastaavia poikkeamia yleisemmästä laulutavasta Arhipalta löytyy myös muualta, ja olenkin taipuvaisempi näkemään sen hänen laulajuutensa ominaispiirteenä: irrallinen, turha ja tarpeeton piirre saa väistyä. Arhipan aukottomuus on usein suoraviivaisuutta, ei hyvää laulutapaa normittava vaan yksilöllinen ominaisuus.

\section{Kerääjien kertomaa}

Kolmantena elementtinä tässä vanhimmassa Arhippa-kuvan kerrostumassa ovat runonkerääjien kertomukset Arhipasta ja keruutilanteista. Erityisen siteerattu on Lönnrotin julkaisema kuvaus siitä, miten Arhippa pienenä nuotalla ollessaan kuuli ja oppi isänsä runolaulua ja miten "nykyään" - keruuaikana 1830-luvulla - runoja ei enää lauleta ja arvosteta niin kuin ennen. Lönnrot esittää kuvauksen suoraan Arhipan lausumana, mutta tekstin eri versioita vertailemalla voi todeta, että se on selvästi Lönnrotin muistikuvistaan muokkaama kuvaus. Sitä luetaan usein suorana etnografisena dokumenttina runojen oppimisesta, mitä se ei kuitenkaan ole. Kuvaus on nähtävä muutaman detaljin varaan rakennetuksi yleistykseksi, joka asettaa rinnakkain runolaulun aseman ennen ja nyt - luonnollisesti entisyyden eduksi. (Lönnrot 1835; Lna 35:3; Lönnrot 1993, 122-125.) Yhtä kaikki, Arhippa hahmottuu ja hän myös hahmottaa itsensä edustamaan sekä runolaulun menneisyyttä että sen jatkumoa, joka kuitenkin oli nyt katkeamassa. Vaikka tiedämme, ettei näin ollut vielä tuolloin käymässä, jostain muutoksesta Arhipan huoli kuitenkin kertoo. Tulkitsen sen liittyvän laulun konteksteihin: tilanteisiin ja tilaisuuksiin, joissa runoja esitettiin. Tilanteita, joissa "kaiket yökauet" kestävää runolaulua on ollut tapana harjoittaa, ei ehkä enää ollut, tai runolaululla ei ollut niissä enää etusijaa, kuten Arhippa valitteli.

Toinen kerrostuma alkaa rakentua 1870-luvulla, kun uusi tutkijasukupolvi palaa Vienaan. Ratkaisevan tärkeässä osassa tässä vaiheessa oli nuori maisteri Aksel August Borenius, joka keruumatkallaan vuonna 1871 päätti etsiä Latvajärvestä Arhipan runojen jälkiä. Näin hän löysi Miihkalin, Arhipan pojan. Vasta tässä vaiheessa saamme myös tietää Arhipan sukunimen. Miihkalin runojen lisäksi Borenius kirjoitti nimittäin muistiin muistitietoa Perttusen suvusta. Tällä on ollut kauaskantoiset seuraukset. Borenius sai tietää, että Arhipan isänisänisä Homa, tai tämän isä, oli tullut Suomesta Oulujokivarresta. Borenius esitti kirjoitelmassaan Missä Kalevala on syntynyt (Borenius 1873) teorian runojen länsilähtöisyydestä. Perusteet olivat pitkälle kielellisiä, mutta kertomukset runonlaulajasukujen lähtöseuduista läntisemmässä Suomessa ovat myös perusteluissa vahvasti mukana. Kuten Jouko Hautala toteaa, Borenius esitti tässä ensimmäisenä opin kansanrunouden vaeltamisesta, jolle ajatukselle rakentui 1800-luvun lopulla syntynyt suomalainen kansanrunoudentutkimus (Hautala 1954, 181-182). Vaikka nykyään tiedämme, ettei asutuksen alkuperää saati geeniperimää voida suoraan samaistaa runojen alkuperään tai syntyyn, jäi ajatus elämään. On kiistelty suvun alkuperästä, ja yhä kiistellään. Vaikka nimellisesti kyse on ollut suvuista, pohjimmiltaan puhe on ollut kalevalaisen runon tai itse Kalevalan alkuperästä ja tekijyydestä. Arhipan suvun alkuperä on ollut kiistoissa mukana, mihin on vaikuttanut sekä Arhipan maine "hyvänä"laulajana 
että käsitys sukuperinteen jatkuvuudesta. Ja erityisesti tätä käsitystä on ollut osaltaan rakentamassa Lönnrotin edellä mainittu kertomus Arhipan runojen oppimisesta.

Boreniuksen kirjaamissa muistoissa Arhippa oli työteliäs, vahva, kylän edusmies. Laulajuutta niissä ei kuitenkaan mainita. Pojalta Miihkalilta on tallennettu monia runoja, jotka muistuttavat suuresti Arhipan vastaavia runoja. Isältä perittyjä ne eivät kuitenkaan kokonaisuudessaan ole. Sen verran selvästi kylän ja lähiseutujen muiden laulajien laulutapa näkyy Miihkalin toisinnoissa.

Jo Boreniuksen muistiinpanoissa esiintyy tieto Arhipan isän Suuren livanan kahdesta veljestä, Pienestä livanasta ja Ivaskosta, eli "pienimmästä" livanasta. Silti tutkimuksessa ja kirjallisuudessa on kuitenkin myöhemmin puhuttu pelkästään Suuresta livanasta, jonka attribuutti Suuri on yhdistetty hänen henkilökohtaisiin ominaisuuksiinsa. livana on "suuri" laulaja, "suuri" tietäjä, johon Lönnrotin kertomus viittaa, tai "suuri" ja vahva mies kuten Arhipankin muistetaan olleen. Arkipäiväinen selitys tälle suuruudelle on kuitenkin se, että Suuri livana oli tässä livana-nimisessä veljessarjassa vanhin. Isä myös poistui Arhipan elämästä jo Arhipan ollessa noin kuuden ikäinen, kun hänet vietiin sotaväkeen (Pöllä 1997, 168-170).

\section{Arhippa ja tutkijat}

Näiden kahden kerrostuman päälle rakentuu suurin osa myöhemmästä Arhippa-käsityksestä niin tutkimuksissa kuin kirjallisuudessakin; sitä toistaen, tulkiten ja sen varaan kehittäen. Arhippaa on harvemmin tulkittu suoraan hänen runojensa kautta. Silloin kun hänen runotekstejään on tutkittu, hänet on nähty runolaulannan yleisenä tai tietyn alueen "edustajana". Wolfgang Steinitz selvitti 1930-luvulla Arhipan tekstien kautta parallelismia (Steinitz 1934). Matti Sadeniemi tutki 1950-luvulla runomittaa ja alkusointua. Sadeniemen tutkimuksessa Arhippa edusti yksin pohjoista runoperinnettä, kun taas eteläisempien alueiden korpus oli koottu useamman laulajan teksteistä. (Sadeniemi 1951.)

Oma tutkimuksenikin kuuluu samaan ryhmään Steinitzin ja Sadeniemen kanssa: tutkin Arhipan runojen poeettisia piirteitä ja syntaksia, jotta voitaisiin tehdä päätelmiä näistä piirteistä koko runolaulukulttuurin kannalta. Olen kuitenkin oppinut varovaiseksi: Arhippa on erityinen laulaja, jonka ominaisuuksien yleispätevyydestä ei vertailematta voi sanoa mitään varmaa. Arhipan edustavuudesta voi keskustella, mutta on vältettävä puhumasta Arhipan esimerkillisyydestä, siitä, että Arhipan laulutapa olisi jollain tapaa normi. Se on yksi vaihtoehto monien joukossa, mutta ei sen oikeampi vaihtoehto kuin muidenkaan laulajien.

Suomalaisen tutkimuksen suhtautuminen runonlaulajiin on aiemmin ollut kaksijakoinen. Toisaalta laulajia on ihailtu ja arvostettu heidän jälkipolville säilyttämänsä perinnön vuoksi. Toisaalta laulajalle ei suotu runojensa tekijyyttä, vain muistajan, esittäjän ja eteenpäin välittäjän rooli. Olisi liioiteltua sanoa, etteivät tuon ajan tutkijat olisi havainneet runotekstien variaatiota ja ymmärtäneet sen johtuvan myös laulajien kyvyistä "runollisesti elävöittää esitystänsä" kuten Kaarle Krohn kirjoitti vuonna 1918. Katse oli kuitenkin menneisyydessä, runon alkuperäisessä muodossa. Muutokset, joita kuvattiin Krohnin "ajatuksen laeilla" tai Martti Haavion mukaisesti "alistumisella noudattamaan sosiaalisessa ryhmässä hyväksyttyjä eepillisiä lakeja" (Haavio 1949, 14), olivat merkittäviä, koska ne olivat osa sitä kehitysketjua, jota seuraamalla voitaisiin päästä käsiksi alkuperäiseen. Mutta ne eivät olleet luovuutta, uutta, eivät edes Arhipan tapauksessa, vaikka hänen runojaan olisi muuten kuinka ylistetty. 
1960-luvulla alkanut folkloristisen paradigman murros siirsi tutkimuksen painopisteen perinneteksteistä ja niiden historiasta perinnetekstien käyttöön ja käyttäjien antamiin merkityksiin ja käsityksiin: lyhyesti kontekstiin. Perinnettä käyttävät ja taitavat yksilöt nousivat samalla enemmän esille myös tutkimuksen kohteena. Runolaulun kohdalla ongelma oli, miten yksilö saattoi näkyä taattisiksi tai hitaasti muuttuviksi käsitetyissä kertovissa teksteissä. Lyriikassa yksilön ja tekstin suhteesta oli kirjoiteltu jonkin verran jo aiemminkin, mutta tieteellisessä diskurssissa eeppinen, myyttinen ja arkaainen olivat vallitsevia. Ja juuri tähän kategoriaan Arhippa on tavallisesti sijoitettu.

\section{Suullis-formulainen koulukunta ja kalevalainen runorekisteri}

Ratkaisevan tärkeäksi tekstin ja yksilön suhteen uudelleen määrittelyssä on osoittautunut amerikkalaisen filologin Albert Bates Lordin vuonna 1960 julkaisema teos The Singer of Tales (Lord 1960). Se synnytti folkloristiikkaan kokonaisen koulukunnan, jota on kutsuttu suullis-formulaiseksi koulukunnaksi, tai "lordilaisuudeksi". Lordin teos kuvaa serbokroatialaisia pitkän eeppisen runolaulun taitajia ja heidän laulujaan. Lordin pääteesit voisi tiivistää kolmeen: 1) jokainen esitys on uusi laulu, 2) laulu luodaan esitystilanteessa, esityksenmyötäisesti ja 3) esityksenmyötäisen komposition tekevät mahdolliseksi laulajan hallitsemat yksiköt ja rakenteet, joista huomattavimpia ovat formulat eli tiettyä keskeistä ideaa toistuvasti esittävät säkeet ja säkeenosat. Tästä johtaen, kun jokainen esitys on uusi tilanteessa syntynyt laulu, mitään kiinteää tekstiä ei ole eivätkä säkeet kuulu vain tiettyyn lauluun. Tämä on ääritulkinta, mutta juuri tällaisena ääritulkintana teoriaa oli aluksi tapana esitellä. Kun teorian innoittamana aloitin omaa tutkimustani Arhipan ja hänen poikansa runoista, teoriaan suhtautuminen oli vielä epäilevää tai korkeintaan varovaisen myönteistä. Kun kaksikymmentä vuotta myöhemmin palasin kysymyksenasetteluuni Arhipan runojen kanssa, teoriasta oli tullut jo yleisesti hyväksytty ajatustapa ja vahvasti osa vallitsevaa paradigmaa. Ei ole enää tavatonta kutsua laulajaa "runoilijaksi" tai olettaa, että lauluteksti syntyy esitystilanteessa. Kehitys tähän tilanteeseen on kuitenkin vaatinut teorian terävimpien särmien tasoittelua ja sen tunnustamista, että eri perinteet voivat erota suuresti toisistaan tekstin tuottamisen perusteissaan.

Kun nyt tutkimuksessani käsittelen Arhipan runotekstien ominaispiirteitä, lähtökohtana on ajatus, että niiden kieli muodostaa systeemin, joka sekä määrittää ilmaisun tavat ja rajat että tarjoaa keinoja ja rakenteita niiden toteuttamiseen. Runotekstiä voidaan luoda esityksenmyötäisesti, esitystilanteessa. Olennaisempaa on oman käsitykseni mukaan kuitenkin se luova työ, joka tapahtuu jo runoa opittaessa ja omaksuttaessa. Samat kielellisen ilmaisun keinot ja rakenteet ovat käytössä molemmissa vaiheissa.

Kutsun tätä systeemiä runorekisteriksi. Termi rekisteri tarkoittaa kielimuotoa, jonka käyttö kytkeytyy tiettyihin tilanteisiin. Termin voima on siinä, että se viittaa kieleen, kun taas esimerkiksi perinnelaji voidaan erottaa muidenkin kuin kielellisten kriteerien avulla. Voisi puhua myös runokielestä, mutta kyseessä on kielen osa-alue, ei itsenäinen erillinen kieli.

Runorekisterin primaarit ominaisuudet ovat sen mitallisuus, alkusointuisuus ja parallelismi eli kerrollisuus. Sekundäärejä piirteitä taas ovat erityisesti arkaaiset tai erikoiset sanat, poikkeavat sanajärjestykset tai vaikkapa toistuvien formuloiden käyttö. Mitallisuus jakaa tekstin äänteellisesti määrittyviin perusyksiköihin, säkeisiin. Säe ei kuitenkaan ole mikä tahansa tietyn tavuluvun ja tavulaajuuden täyttävä sanajono, vaan se on samalla syntaktis-semanttinen 
perusyksikkö. Muistinvaraisessa, suullisesti välittyvässä ja pelkästään kuultavassa runoudessa syntaktis-semanttisen ja mitallisen rakenteen välinen vastaavuus on hyvin luonnollista, koska siten säkeet lohkeavat luonnollisista saumakohdistaan ja niiden liittäminen varioivin tavoin toisiinsa on helpompaa. Näin ne mahdollistavat myös runoillemme tyypillisen säekerron laajan viljelyn; niin laajan, että säekertoa, samoin kuin alkusointua, voi pitää yhtä pakollisena ominaisuutena kuin runomittaa.

Kalevalainen runorekisteri on ollut monikasvoinen poeettisen ilmaisun muoto. Se on ollut musiikkia, eri tavoin esitettyä runolaulua. Se on ollut loitsua, saneltua, innoittuneesti puheltua tai ehkä laulaenkin esitettyä pyrkimystä vaikuttaa ihmiselämän kannalta kriittisiin tapahtumiin ja vaiheisiin. Se on ollut sananlaskua, muinaista ja joskus uudempaakin viisautta asioiden tilasta. Kun sama rekisteri on ollut yhteinen näille kaikille lajeille, sen ainekset, rakenteet ja ajatukset ovat voineet helposti liikkua lajista toiseen. Runorekisterissä mitallisuus, äänteellisyys ja kerrollisuus on ollut normaalikielestä poikkeava, yhteisön jakama, arvostama ja harjoittama syvään juurtunut, luonnollinen ajatustapa. Nykyihmiselle ajatustapa voi olla vaikea, hämärä ja kaikessa kerrollisuudessaan puuduttava. Se on kuin vieras kieli, jota voi oppia ja opetella mutta jonka merkityksistä ja vivahteista ei koskaan voi olla täysin varma.

Kun käyn läpi Arhipan runokorpusta, pystyn erottelemaan ja kuvaamaan monenlaisia, poeettisiksi tarkoitettuja rakenteita, mutta monesti olen joutunut miettimään, ymmärränkö kaiken samoin kuin itse laulaja tai hänen kuulijansa: jaanko minä heidän kokemustaan millään tavoin?

\section{Mitä Arhippa lauloi?}

Mitä Arhippa sitten lauloi? Arhippa tunnetaan parhaiten kertovista runoistaan, joita hänellä oli ainakin 3000 säkeen verran. Keskeisten Kalevala-aiheisten runojen ohella esille nousevat uskonnolliset runot. Näitä runoja on neljä ja säemäärältään ne kattavat melkein viidesosan Arhipan kertovista runoista. Laajin on Luojan virreksi kutsuttu kokonaisuus. Runossa kuvataan Jeesuksen elämänkaari: Neitsyt Marian marjanpoiminta ja raskaaksi tuleminen, Jeesuksen syntymä saunassa ja sen jälkeinen katoaminen. Neitsyt Maria lähtee etsimään lastaan ja kyselee vastaan tulevilta tieltä, kuulta ja auringolta pojan olinpaikkaa. Muut Vienan laulajat kertovat tämän jälkeen, miten aurinko lopulta ilmaisee pojan olevan kiven alla, eli kuolleena, ja jatkavat runolla, joka kertoo ylösnousemuksesta ja kuoleman voittamisesta. Arhippa sen sijaan antaa auringon ilmoittaa, että poika on jo taivaassa. Arhipalta muistiinpannuissa versioissa vaihtelevat mielenkiintoisesti esikristillisen kerrostuneen taivaskuvan elementit ja kristillinen, uskontunnustuksellinen lopetus: aurinko kertoo, että poika on

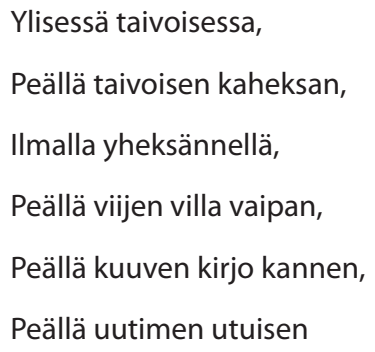


Ylisessä taivoisessa,

Isän Jumalan sijalla,

Tulou sieltä tuomittsemah

- tekisi mieli jatkaa eläviä ja kuolleita. Arhipan runon loppu on uniikki, ja kerroksellisen taivaskuvan elementit ovat samat kuin hänen Tulen synty -loitsussaan, jossa Ilmarinen ja Väinämöinen iskevät tulta taivaassa. Onkin mielestäni hyvä syy olettaa, että tässä näkyy Arhipan oma maailmankatsomus ja oma luova panos.

Kirkonkirjoissa Arhippa esiintyy useamman kerran kummina tai vihkimisen todistajana. Kerääjät, niin Lönnrot kuin M. A. Castrén, kiittivät erikseen Arhipan suvaitsevaisuutta, kun hän antoi vieraiden käyttää samoja astioita ja salli jopa tupakoinnin tuvassa (Castrén 1852). Arhippa ei näyttäisi siis olleen seudun näkyvimmän uskonnollisen liikkeen eli vanhauskoisuuden, kannattaja. Mikä hänen uskonnollisen ajattelunsa tausta oli, sitä en tiedä. Se voi ilmetä myös siinä, että hän sensuroi Sampo-runostaan Maailmansynty-episodin, tai siinä, miten hän Lönnrotin mukaan paheksui nykyajan riettaita "tyttöjen ja poikien ilveasioista" kertovia lauluja.

Castrén kiersi Vienan Karjalaa vuonna 1839 etsien tietoja suomalaisesta mytologiasta. Hän meni tapaamaan myös Arhippaa, ja pettyi, kun Arhippa väitti, ettei hän taitanut Castrénin erityisesti haluamaa loitsuperinnettä. Viisi vuotta aiemmin Elias Lönnrotin läsnäollessa hän oli kuitenkin esittänyt noin tuhannen säkeen verran pitkiä syntyloitsuja. Miksi hän sitten Castrénin edessä tekeytyi osaamattomaksi? Syyt voivat olla moninaiset: henkilökemia, kiire, unohdus. Uskon kuitenkin, että syy piilee Arhipan suhteessa tietäjäntoimeen. Vihje tähän voi löytyä Johan Fredrik Cajanin muistiinpanoista; Cajan oli kolmas Arhipan tavannut runonkerääjä. Yhden keruukäsikirjoitussivun alalaitaan on sijoitettu lyhyt parin lauseen kirjaus: "Onhan ne tietohussanat juuri kuin luonnon nossatukset. Kun se luonto vaan liikkuupi, niin vähä niitä sanoja tarvihteisi." (Cajan 3:481b.) "Tietohussanat" voisivat olla syntyloitsuja. "Luonnon nossatukset" viittaavat tietäjän haltioitumiseen tähtääviin nostatussanoihin. "Luonnon liikkuminen" on haltioitumista. Eli tietohussanat toimivat kuin luonnon nostattaminen. Mutta jos tietäjän luonto "liikkuu", hän ei näitä sanoja tarvitse niin paljon. Tulkitsen: Oikea tietäjä pystyy liikuttamaan luontoaan. Arhippa ei tähän pystynyt, hän ei ollut tietäjä. Tähän ei viittaa myöskään perimätieto, eivätkä kerääjät mainitse sitä. Castrén sanoo Arhipan pitäneen tietäjälaitosta synnillisenä. Olisiko Castrén yrittänyt saada loitsuja käyttämällä tietäjän toimen harjoittamiseen viittaavaa kysymystä?

Loitsuperinteen taitaminen oli 1800-luvun Vienassa yleistä. Melkein jokainen vähänkään runoja taitava osasi niitä jollain tavalla. Läheskään kaikki perinteentaitajat eivät kuitenkaan profiloituneet tietäjiksi. Arhipan kohdalla arvoituksellista on hänen loitsuperinteensä laajuus ja luonne. Loitsut olivat pitkiä, kokonaisvaltaisia parannusnäytelmiä syntykertomuksineen, manauksineen ja avunpyyntöineen. Käyttikö hän niitä? Oliko niiden esittäminen Lönnrotille vain tietäjäimitaatiota, kun Arhippa on halunnut esittää Lönnrotille kaiken minkä osasi? Ehkä vähän molempia. On myös muistettava, että nämä loitsutkin ovat runoja, joiden esittämistä ohjaavat samat poeettisen ilmaisun tarpeet ja säännöt kuin muutakin runoutta. Olennaista ei ole vain funktio ja sisältö, olennaista on myös muoto. 


\section{Lopuksi}

On esitetty, että Arhipan runorepertuaari olisi ollut huomattavasti suurempi, jos kerääjät olisivat ehtineet viettää hänen kanssaan enemmän aikaa. Kertovien runojen suhteen epäilen tätä. Arhippa osasi suurimman osan niistä kertovista runoista, joita alueella laulettiin. Kiinnittäisin kuitenkin huomiota siihen pieneen osaan hänen tallennettua repertuaariaan, jota voisi luonnehtia lyriikaksi ja mietelmärunoiksi. Nämä runot tuntuvat muodostavan avoimen luokan, jossa ei ole juuri kiinteitä kokonaisuuksia vaan enemmänkin aiheita tai säkeitä ja säepareja, jotka yhdistyvät eri tavoin eri yhteyksiin. Erityisen huomionarvoisaa on sananlaskujen runsaus Arhipan teksteissä. Sananlaskut voivat olla osana muuta tekstiä, mutta niiden varaan voi rakentua kokonainen mietelmärunokin. Ne toimivat assosiaatioiden kautta, tilannesidonnaisesti, esityksenmyötäisen komposition varalla. Siksi niitä on hyvin vaikea kerätä kertomarunojen tai loitsujen tavoin. Näitä runoja olisi todennäköisesti voitu tallentaa Arhipalta loputtomiin, jos olisi ollut aikaa ja oikeat menetelmät.

Arhipan runojen tutkimus on vienyt minut yhtäältä kielentutkimuksen syövereihin ja kvantitatiiviseen analyysiin - syvemmälle kuin koskaan olisin arvannut. Näin on ollut kuitenkin tehtävä, jotta pystyisin kuvaamaan eksaktisti sen, miten Arhippa lauloi: miltä laulu kuulosti, miten se rakentui, miten se merkitsi. Vaikka en olisi varma, että muut lauloivat samoin, uskon että Arhipan kuvauksesta voi olla apua, kun rakennetaan yleisempää kuvausta runolaulun rakenteista ja poetiikasta. Toisaalta tutkimus on vienyt minut vihjeiden hakuun. Kun taustatietoa on vähän, olettamuksia pitää tehdä detaljien kautta. En voi varmasti tietää, mitä Arhippa ajatteli loitsuista ja tietäjälaitoksesta, en voi tietää, mistä hän todella puhui Lönnrotin kanssa. En myöskään voi tietää, keneltä Arhippa on runonsa oppinut, mutta päättelen: monelta. En voi myöskään tietää, heijastuuko Arhipan teksteissä vanha Perttusen sukuperinne, kuten monesti on sanottu, vai onko siinä merkittävämpiä kerrostumia muualta, esimerkiksi hänen etelävienalaisen äitinsä kotiseuduilta: tekstit sisältävät itse asiassa useita viitteitä ällistyttävän eteläisiin, suorastaan inkeriläisiin yhteyksiin. En osaa niitä kunnolla selittää. Teen olettamuksia ja arvelen, olen joskus ehkä oikeassa, mutta varmaan useasti väärässäkin. Kuitenkin, ilman uskallusta olettaa tieto ei lisäänny. Näin Arhippa Perttusen runot avaavat meille ikkunaa menneisyyteen, ei niinkään siihen muinaisuuteen, jossa runoperinteen juuret sijaitsevat, vaan siihen runoperinteeseen, jossa Arhipan oman laulun juuret ovat. Ehkä runolaulu oli muutoksessa, kun Elias Lönnrot Arhipan ensi kertaa tavoitti. Mutta niin se on ollut aina ja on vieläkin.

Saarinen, Jukka. 2018. Runolaulun poetiikka: Säe, syntaksi ja parallelismi Arhippa Perttusen runoissa. Helsinki: Unigrafia. URN:ISBN:ISBN 978-951-51-3919-1 (PDF). http://hdl. handle.net/10138/228692 


\section{Lähteet}

\section{Arkistolähteet}

Suomalaisen Kirjallisuuden Seuran arkisto, Kirjallisuuden ja kulttuurihistorian kokoelma:

Axel August Boreniuksen arkisto. Kotelo 1: Vuosien 1871-1872 keruumatkojen matkakertomuksia, päiväkirjoja ja muistiinpanoja laulajista sekä sävelmistä. 2:35-2:37, 2:40.

Lönnrotiana-kokoelma (Lna). Sidokset Lna 35, Lna 36, Lna 78, Lna 79, Lna 99.

Suomalaisen Kirjallisuuden Seuran arkisto, Perinteen ja nykykulttuurin kokoelma:

Cajan, Johan Fredrik. Sidos 3.

\section{Kirjallisuus}

Borenius, A. A. 1873: Missä Kalewala on syntynyt?: Tutkimuksia suomalaisen kansanrunouden alalla. Helsinki: Suomalaisen Kirjallisuuden Seuran Kirjapaino.

Castrén, Matias Aleksanteri 1852: Nordiska resor och forskningar. Första bandet, M. A. Castréns reseminnen från åren 1838-1844. Helsingfors: Finska Litteratursällskapets tryckeri.

Haavio, Martti 1949: Kansanrunojen sepittäjät ja esittäjät. - Virittäjä 53, 6-15.

Hautala, Jouko 1954: Suomalainen kansanrunoudentutkimus. SKST 244. Helsinki: SKS.

Krohn, Kaarle 1918: Kalevalankysymyksiä. Opas Suomen kansan vanhojen runojen tilaajille ja käyttäjille ynnä suomalaisen kansanrunouden opiskelijoille ja harrastajille. 1-2. Helsinki: Suomalais-ugrilainen seura.

Lord, Albert B. 1960: The singer of tales. Cambridge (MA): Harvard University Press.

Lönnrot, Elias 1835: Kalewala taikka wanhoja Karjalan runoja Suomen kansan muinosista ajoista. SKST 2. [Helsinki]: SKS.

Lönnrot, Elias 1993: Valitut teokset. 5, Muinaisrunoutta. Toim. Raija Majamaa. SKST 580. Helsinki: SKS.

Pöllä, Matti 1997: Perttusen suvun vaiheet 1700-luvulla. - Karjalan heimo 81:11-12, 168-170.

Sadeniemi, Matti 1951: Die Metrik des Kalevala-Verses. FFC 139. Helsinki: Suomalainen tiedeakatemia.

SKVR I = Niemi A. R. (toim.) 1908-1921: Suomen Kansan Vanhat Runot I. Vienan läänin runot. Helsinki: SKS.

Steinitz, Wolfgang 1934: Der Parallelismus in der finnisch-karelischen Volksdichtung. FFC 115. Helsinki: Suomalainen tiedeakatemia.

Jukka Saarinen toimii kehittämispäällikkönä Suomalaisen Kirjallisuuden Seuran arkistossa. 


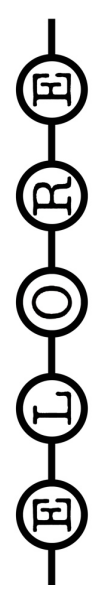

